\title{
Energy Consumption and Energy Management in Precision Machinery Industry
}

\author{
Yueh-Ling Lin, Chih-Chieh Lin, and Hung-Sheng Chiu \\ Central Industry Research \& Service Division, CID, \\ Institute for Information Industry, \\ 7 Guangming Road, Chung Hsing New Village, \\ Nantou City, Nantou County, Taiwan 54071, ROC \\ email: yuehlin@iii.org.tw, erir@iii.org.tw, bbchiu@iii.org.tw
}

\begin{abstract}
Keywords: Energy data acquisition; Energy consumption; Energy profile analysis; Energy management; Precision machinery industry; Overall equipment efficiency
\end{abstract}

\begin{abstract}
This study develops a machine tool consumption and energy management platform. The proposed method established a variety of electricity profile in order to differentiate various processing status in machining conditions. The platform provides energy related application services, including machine monitoring service and alarm service. It not only helps enhance the efficiency of energy usage in precision industries, but also helps decrease the costs of electricity for manufacturers. Thus, the project will help promote green manufacturing, environmental protection, energy saving, and sustainable management capabilities. Finally, the results will drive these energy management issues as the core values in precision industries.
\end{abstract}

\section{Introduction}

According to global trends in green energy, the topics on environmental protection and energy saving have become more popular in international industries [1, 2]. The future energy policy will decide to address the issues of energy consumption and energy management to be included in related machinery equipment $[3,4]$. In order to help domestic industries quickly react to market changes, it is necessary to upgrade these domestic industries to have the capability of using energy efficiently [5]. With the increasing electricity costs in domestic industries, it lacks integrated solutions and needs further study to solve these problems in energy consumption and energy management [6].

Currently, the advanced technology integrated and collected the overall information from precision machinery factory for the development of the manufacturing energy analysis and management [7]. To enhance the overall equipment efficiency, it is necessary to improve the elasticity in supply chain management by achieving an innovative energy management model for manufacturing service application [8]. With the development of electricity and monitoring middleware, the captured electricity information can be processed and transmitted for further management applications [9]. It can support the commercial electricity detection from spindle servo motor and PLC controller and collect the processing parameters of the machinery equipment [10].

In order to solve these problems, this project uses information and communication technology (ICT) to acquire energy data for further energy profile analysis. The acquired energy data can help to distinguish various machine statuses from operation. In this way, it will help conduct related services for energy consumption, energy profile analysis, energy management, and etc. This project not only helps precision industries to improve energy usage and energy efficiency during operation, but also helps provide strategies for upcoming trends in green energy and potential ways of production.

\section{Method}

The system uses the power meter to detect the amount of electricity from the spindle and servo axes of machine tool equipment. The electricity information including speed, feed rate, tool usage, 
load data can be subsequently collected in to the electricity sensing module. The process program such as the $\mathrm{G}$ code provides detailed information about equipment and components electricity. Fig. 1 illustrates the process to collect electricity information from a variety of machine tool equipment. The data was collected by wireless sensing technology from cross-brands of products. The platform collects the related electricity information for establishing further electricity profile.

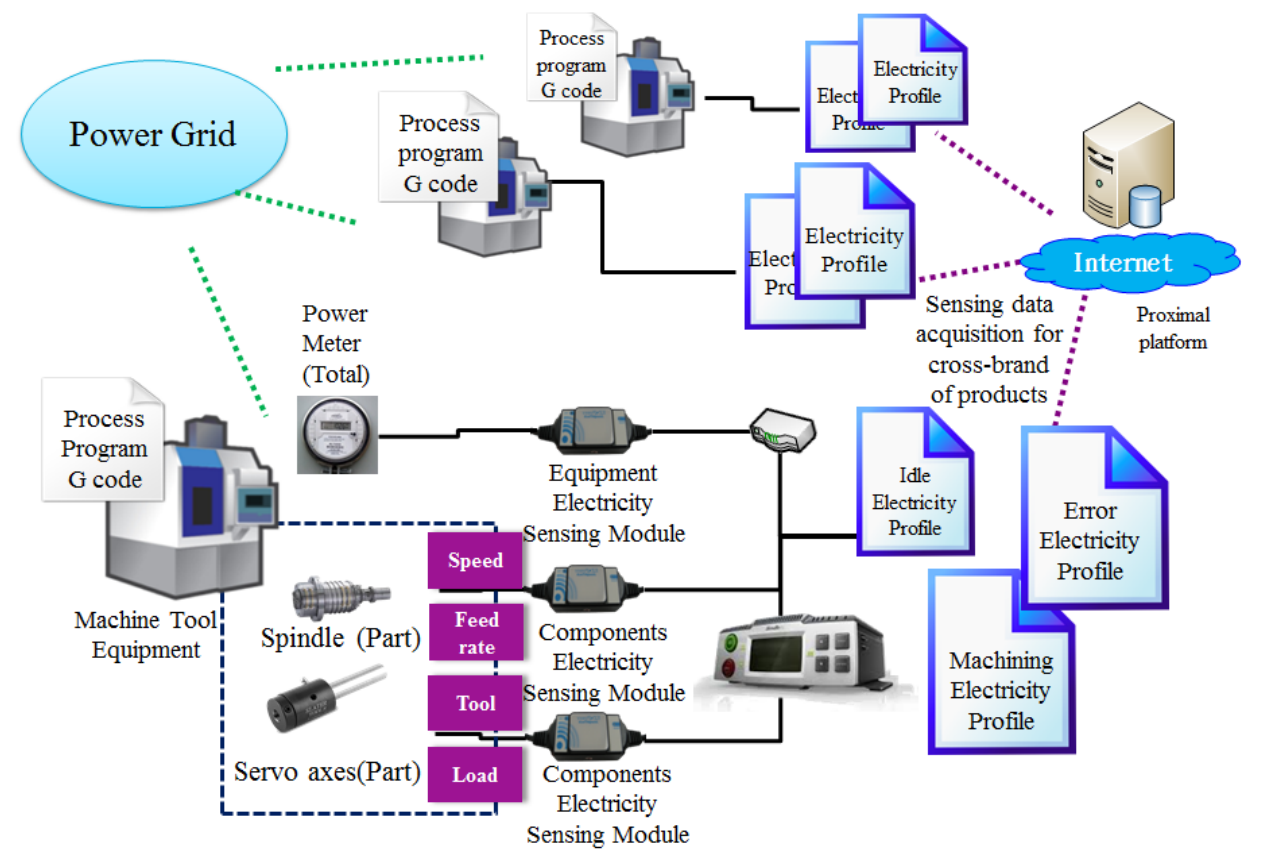

Fig.1. The process to collect electricity information from a variety of machine tool equipment.

The information was gathered from the NC program, work piece, tool cutting process, CNC spindle speed, and CNC feed rate. The obtained information was transmitted and saved in the ServBox for later data analysis. There are three kinds of database in the ServBox including machine electricity feature database, tool electricity feature database, and workpiece electricity feature database. These database collected data from machines to calculate the energy usage from the process of cutting path. The power estimation method analyzed the electricity feature data and produced the reports for power consumption, tool usage, and motor electricity. The framework of the energy consumption analysis model was illustrated in Fig.2.

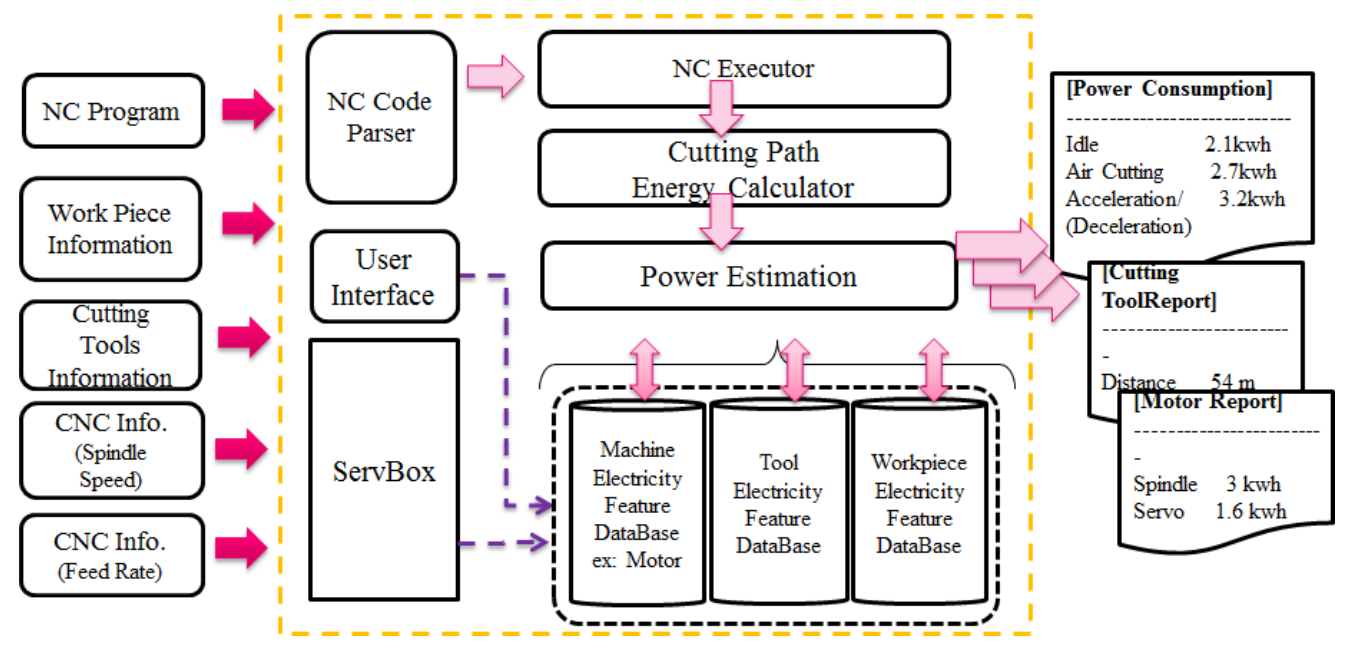

Fig.2. Energy Consumption Analysis Model

Through analysis of energy usage and consumption, the results help reduce the amount of energy utilization rate with the period of no operation. Thus, the proposed method enhances the electrical efficiency in precision and mechanical environment. Moreover, the developed platform provides electricity application service for energy management in precision industries. 
In order to establish the electricity profile for energy management, an efficient energy management process was proposed. For the process, the study established the framework for energy data acquisition and data process. First, the energy data was collected by ServBox. The obtained data include machine electricity, equipment electricity, and time. There are three status including idle check, empty cut check, and process check before start the process for energy data acquisition. If the status check was satisfied, the electricity profiles are subsequently established for the idle, empty cut, and machine tool process. These profiles were combined together and saved in knowledge base for the development of the referenced electricity value. The prebuild data including machine idle electricity and spindle speed electricity can be used for later energy related analysis and evaluation.

In order to provide platform for electricity analysis and service application, the acquired data from machine tool and internal components was transferred through the Ethernet of TMTC energy parameter. The large machine data was saved in four different profiles including idle profile, tool exchange profile, warm-up profile, and machining profile. These data was then analyzed by the developed middleware platform to provide abnormal electricity alarm through TCP/IP. The electricity analysis results provide four kinds of energy service application, including electricity historical report, electricity status monitor, energy usage, and machining electricity management. Fig.3 illustrates the platform for electricity analysis and service application.

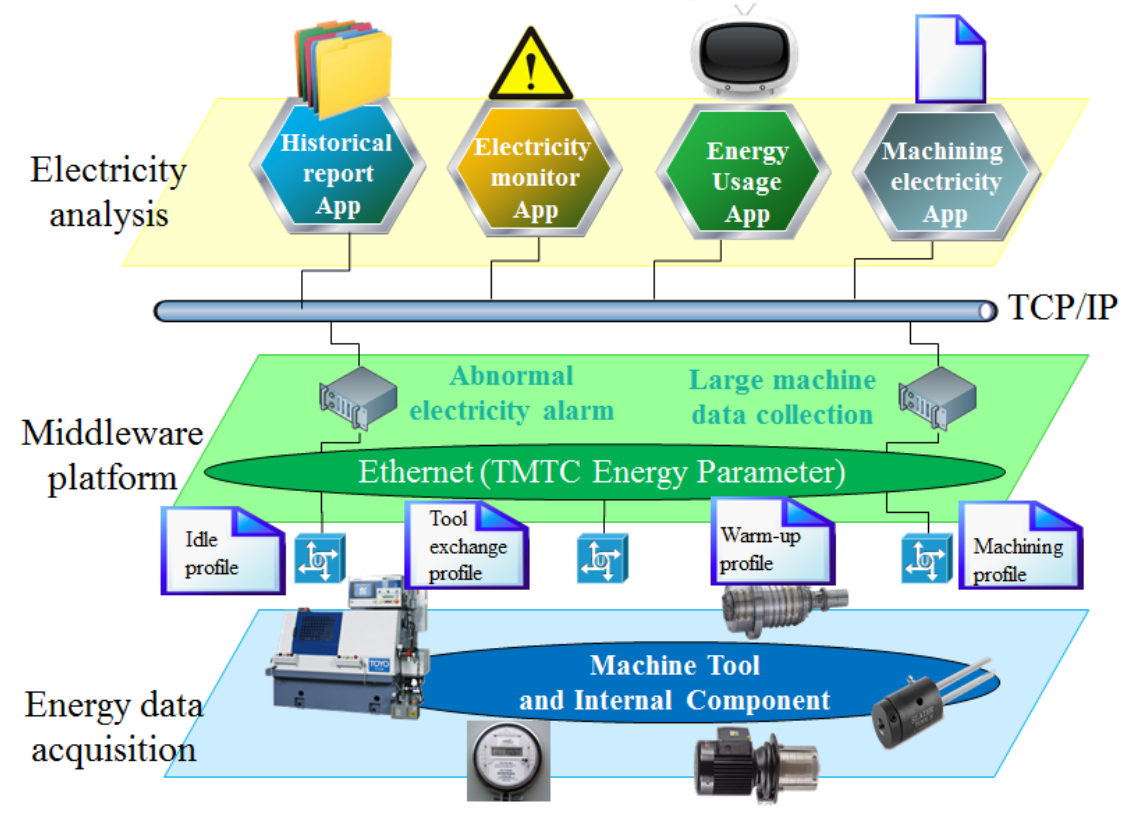

Fig.3. The platform for electricity analysis and service application.

\section{Results and Discussions}

The system detects the electricity from the spindle and servo axes of machine tool equipment based on the proposed electricity sensing module. The equipment and components electricity information such as $G$ code was collected by wireless sensing technology from cross-brands of products. The platform then gathered information from the NC program, work piece, tool cutting process, CNC spindle speed, and CNC feed rate. Three databases include machine electricity feature database, tool electricity feature database, and workpiece electricity feature database was analyzed to calculate the energy usage. The energy consumption analysis model was established and helped reduce the amount of energy utilization rate during machine operation. The results help manufacturers to develop appropriate solutions for integrated perspective to save energy, reduce carbon production, and enhance the overall equipment efficiency in precision industries. 


\section{Conclusion}

This study established the electricity data acquisition and energy management process. The data was collected by ServBox and subsequently combined to establish the related electricity profiles for the referenced knowledge base. The prebuild data can be used for energy analysis and management. In order to differentiate various processing status in machining conditions, this study develops a machine tool consumption and energy management platform. The platform provides energy related application services, including machine monitoring service and alarm service. It not only helps enhance the efficiency of energy usage in precision industries, but also helps decrease the costs of electricity for manufacturers. Thus, the project will help promote green manufacturing, environmental protection, energy saving, and sustainable management capabilities. Finally, the results will drive these energy management issues as the core values in precision industries.

\section{Acknowledgement}

This study is conducted under the "2015 Project of Development of Industrial Platform for Value-Added Service via Intelligent Sensing Technology (2/4)” of the Institute for Information Industry which is subsidized by the Ministry of Economy Affairs of the Republic of China.

\section{References}

[1] Mazak Announces New MTConnect Energy Dashboard, Mazak Corp. http://news.thomasnet.com/companystory/Mazak-Announces-New-MTConnect-Energy-Dashboard581903

[2] International Journal of Mechanical, Aerospace, Industrial and Mechatronics Engineering vol:8, no:6, 2014, Investigation on Machine Tools Energy Consumptions

[3] Aspects of Energy Efficiency in Machine Tools - HEIDENHAIN

http://www.heidenhain.us/enews/stories_1011/MTmain.php

[4] Q. Ning, T. Wang, L. Liu, and Y. Jiang, "Research on CNC Machine Tools Integration Condition Monitoring System and Its Information Exchange Technology," Future Computing, Communication, Control and Management, Lecture Notes in Electrical Engineering, vol. 144, 2012, pp. 441-450.

[5] SMP - Green Machine Tools http://smp.berkeley.edu/?attachment_id=214

[6] Makino Offers MPmax Real-Time Machine Process Monitoring and Data Management http://www.automation.com/product-showcase/makino-announces-mpmax-machine-process-monito ring-software

[7] SMP - Process Monitoring for Energy Efficient Machine Tools

http://smp.berkeley.edu/?attachment_id=198

[8] IEEE - A Methodology to Estimate Power Consumption of Numerical Control Machining

[9] Yueh-Ling Lin, Chih-Chieh Lin, and Hung-Sheng Chiu. “The Development of Intelligent Service System for Machine Tool Industry - The Comparison of Taiwan Machine Tool Connect (TMTC) Standard with the MTConnect Standard”, IEEE International Conference on Industrial Networks and Intelligent Systems (IEEE INISCom), Tokyo, Japan, March 2-4, 2015.

[10] ICT Standards and Intelligent Service Platform Development, Ministry of Economic Affairs in Taiwan, Annual Report, 2013. 